\title{
Deposição de filmes de ZEI $8 \%$ em mol por sistema de spray pirólise modificado
}

\author{
Rodrigues, C.H.M. ${ }^{\mathrm{I}}$; Toniato, M. ${ }^{\mathrm{I}}$; Paes Jr, H.R. ${ }^{\mathrm{I}}$ \\ ${ }^{\text {I }}$ Universidade Estadual do Norte Fluminense/CCT/LAMAV, Av. Alberto Lamego, 2000 - Pq. Califórnia, \\ Campos dos Goytacazes - RJ - Brasil \\ e-mail: cmanzini@gmail.com, mitoniato@gmail.com, herval@uenf.br
}

\section{RESUMO}

Neste trabalho, foram produzidos filmes de zircônia estabilizada com ítria com 8 \% em mol (ZEI), que podem aplicados como eletrólitos para pilhas a combustível de óxido sólido (PaCOS), abrasivos e proteção anti-corrosiva, depositados em substrato de quartzo pela técnica de spray pirólise e tratados termicamente a $1000^{\circ} \mathrm{C}$. Para obtenção dos filmes, foi utilizado um sistema de deposição por spray-pirólise modificado segundo patente depositada no INPI, que se comparado ao sistema tradicional onde o bico atomizador fica estático durante o processo de deposição, resulta na produção de filmes de melhor homogeneidade, rugosidade e na redução dos defeitos morfológicos, como as trincas e fissuras. As melhorias no aparelho de deposição forneceram, também, melhor controle sobre os parâmetros de deposição quando comparado ao sistema tradicional, como a taxa e temperatura de deposição. A estrutura do filme foi analisada através de difração de raios $X$, que se apresentaram policristalinos e de acordo com a identificação realizada com o padrão JCPDS \# 821246, os filmes de YSZ estão arranjados em uma estrutura cúbica de face centrada do tipo fluorita, e com orientação preferencial dos grãos no plano (111). A morfologia dos filmes foi analisada por imagens de microscopia ótica e microscopia de força atômica, sendo comparada às trincas, a rugosidade e distribuição de grãos, para os filmes após o tratamento térmico. Os melhores resultados foram obtidos para os filmes depositados pelo método de spray pirólise modificado quando comparado ao sistema tradicional.

Palavras-chaves: ZEI, eletrólitos, PaCOS e MESP®.

\section{Deposition of YSZ $8 \mathrm{~mol} \%$ films by modified spray pyrolysis system}

\section{ABSTRACT}

In this work zirconia stabilized with itria films $8 \mathrm{~mol} \%$ (8YSZ) had been produced, applied as electrolytes for solid oxide fuel cell (SOFC), deposited in quartz substrate spray-pyrolysis technique and treated at $1000^{\circ} \mathrm{C}$. For attainment of films a system deposition for spray-pyrolysis modified according to patent deposited in INPI was used, that if compared with traditional system where atomized is static during deposition process, results in production of films more homogeneous, roughness and reduction of morphologic defects, at cracks. The improvements in deposition apparatus had also supplied better control of deposition parameters when compared with traditional system, with solution flow rate and temperature of deposition. The structure of films had been analyzed through X-ray diffractometry (XRD) results indicated that polycrystals films, structure cubical centered face of fluorite type with preferential orientation of grains in plan (111) identification through of standard JCPDS \# 821246. The films morphology was analyzed by optical microscopy and atomic force microscopy, being compared cracks, roughness and distribution of grains, for films after thermal treatment. The results indicate that the use deposited in modified method of spray-pyrolysis (MESP®) appropriate deposited films the deposited were dense, crack-free and well adhered to the substrates.

Keywords: YSZ, electrolytes, SOFC and MESP®. 


\section{INTRODUÇÃO}

A pilha a combustível é um dispositivo eletroquímico, que realiza a conversão de energia gerada por uma reação eletroquímica em energia elétrica, sendo um método altamente eficiente de geração de eletricidade e, em alguns casos, de calor [1]. Trata-se de uma tecnologia extremamente eficiente e de concepção ambiental, pois emite concentrações desprezíveis de $\mathrm{NO}_{\mathrm{x}}$, quando comparados a outros processos de combustão [2,3]. As diferentes tecnologias de pilha a combustível têm basicamente o mesmo princípio: são compostas por dois eletrodos porosos - o ânodo (terminal negativo) onde ocorre a reação com o combustível e o cátodo (terminal positivo) onde flui o oxigênio, separados por um eletrólito (material impermeável que permite movimento aos íons positivos entre os eletrodos) [1-6].

A tecnologia de obtenção de pilhas a combustível atualmente apresenta uma grande diversificação para diferentes aplicações, como o tipo de eletrólito determina a temperatura de operação da pilha que é um dos parâmetros mais importantes no seu desenvolvimento, em geral a classificação da pilha é dada de acordo com o material formador do eletrólito [5-9]. As pilhas a combustível de óxido sólido ( $\mathrm{PaCOS}$ ) são estruturas multicamadas consistindo de materiais cerâmicos e metálicos, operando em temperaturas de 600 a $1000{ }^{\circ} \mathrm{C}$. O eletrólito é composto de uma camada cerâmica de condutividade puramente iônica, por onde o eletrodo terá uma abertura para o transporte de seus elétrons, bem como, para os gases reagentes e os produtos da reação [7-13].

As pilhas a combustível de temperatura elevada e intermediária, em especial as com base em óxidos sólidos (PaCOS-AT e PaCOS-TI), apresentam como principais vantagens à possibilidade de obtenção de potência elevada, grande resistência física e química, proporcionando o aumento da vida útil da pilha, trabalho em larga escala, diminuição dos problemas de emissão de poluentes e a redução dos custos de fabricação, que se destaca como principal empecilho à comercialização destes dispositivos [8-13]. A redução dos custos para o desenvolvimento das PaCOS em geral, ocorre na preparação dos filmes utilizados, envolvendo o uso de materiais da pilha (eletrodos, interconectores e eletrólitos) mais baratos e da técnica de preparação, bem como a diminuição da temperatura de operação da pilha objetivando a estabilidade de componentes como os selantes e interconectores. Dentre os métodos de deposição de filmes, pode-se destacar a técnica de deposição química por spray-pirólise, principalmente devido a sua simplicidade, versatilidade, eficiência e principalmente, o baixo custo [10,13,14].

Neste trabalho foram produzidos filmes de zircônia estabilizada com ítria com $8 \%$ em mol (ZEI), que podem ser utilizados como eletrólitos para pilhas a combustível de óxido sólido (PaCOS), depositados em substrato de quartzo e tratados termicamente a $1000^{\circ} \mathrm{C}$ durante 4 horas. Foram obtidas grandes melhorias da morfologia e topologia dos filmes devido às modificações realizadas no sistema de deposição por spray pirólise, quando comparado ao sistema tradicional onde o bico atomizador fica estático durante a deposição, que resultaram na diminuição da rugosidade, numa melhor distribuição dos grãos, redução das trincas e fissuras dos filmes depositados. As modificações do aparelho de deposição que foi intitulado como sistema de deposição de filmes com movimento equatorial por spray pirólise (MESP®), forneceram também melhor controle sobre os parâmetros de deposição, como distância do bico atomizador, taxa de deposição e temperatura de deposição. Assim neste trabalho temos por objetivo comparar a morfologia, estrutura e topologia dos filmes de ZEI quando o mesmo é produzido pela técnica de spray-pirólise tradicional e modificada.

\section{MATERIAIS E MÉTODOS}

\subsection{Preparo da solução de partida e da deposição dos filmes}

A solução precursora que foi utilizada é constituída de uma solução aquosa $0,1 \mathrm{~mol} / \mathrm{L}$, partindo de soluções de $0,082 \mathrm{~mol} / \mathrm{L} \mathrm{ZrCl} 4$ e $0,018 \mathrm{~mol} / \mathrm{L} \mathrm{YCl} 3.6 \mathrm{H} 2 \mathrm{O}$, ambos da Aldrich do Brasil com grau de pureza de $99,99 \%$. Para o inicio da deposição os substratos previamente limpos, foram colocados sobre uma chapa aquecida na temperatura (3) de $350^{\circ} \mathrm{C}$, fazendo incidir um spray da solução salina (1), formado através da inserção de um gás de arraste de ar comprimido com pressão de 1,0 Kgf.cm-2, com o fluxo da solução controlado por uma válvula na saída (2) do reservatório de $30,0 \mathrm{~mL} / \mathrm{h}$. O spray da solução precursora na eminência de entrar em contato com os substratos aquecidos sofre a vaporização dos compostos voláteis da solução, ocorrendo em seguida à reação pirolítica dos solutos, obedecendo à estequiometria química na superfície do substrato, que resultarão na formação de filmes dos óxidos dos materiais precursores Os outros parâmetros utilizados na deposição foram os tempos de deposição de 30 minutos, distância entre bico e substrato $224 \mathrm{~mm}$; temperatura de deposição $300^{\circ} \mathrm{C}$, substratos de quartzo e velocidade bico atomizador 15 30 ciclos/minuto.

As modificações realizadas no sistema de deposição (ver a Figura 1), que foram patenteadas no INPI [15], estão baseadas no movimento horizontal do bico atomizador, a partir de um sistema mecanizado 
desenvolvido na UENF, com o auxilio do laboratório de eletrônica do departamento de Física e de manutenção mecânica do departamento de Materiais. Esta implementação proporcionou a melhoria da distribuição da solução vaporizada sobre a superfície dos substratos durante a deposição, resultando na alteração morfológica dos filmes, tais como: redução na rugosidade e diminuição da quantidade de trincas, quando comparados a filmes depositados pelo sistema tradicional [15-16]. O tratamento térmico dos filmes depositados pelo sistema tradicional e modificado foi realizado em uma forno da EDG equipamentos, modelo EDG3p, com a taxa de $3^{\circ} \mathrm{C}$ por minuto, em atmosfera de ar e temperatura final de $1000^{\circ} \mathrm{C}$. Os filmes permaneceram nesta temperatura pelo tempo de 300 minutos, sendo em seguida resfriados na mesma taxa até a temperatura ambiente.

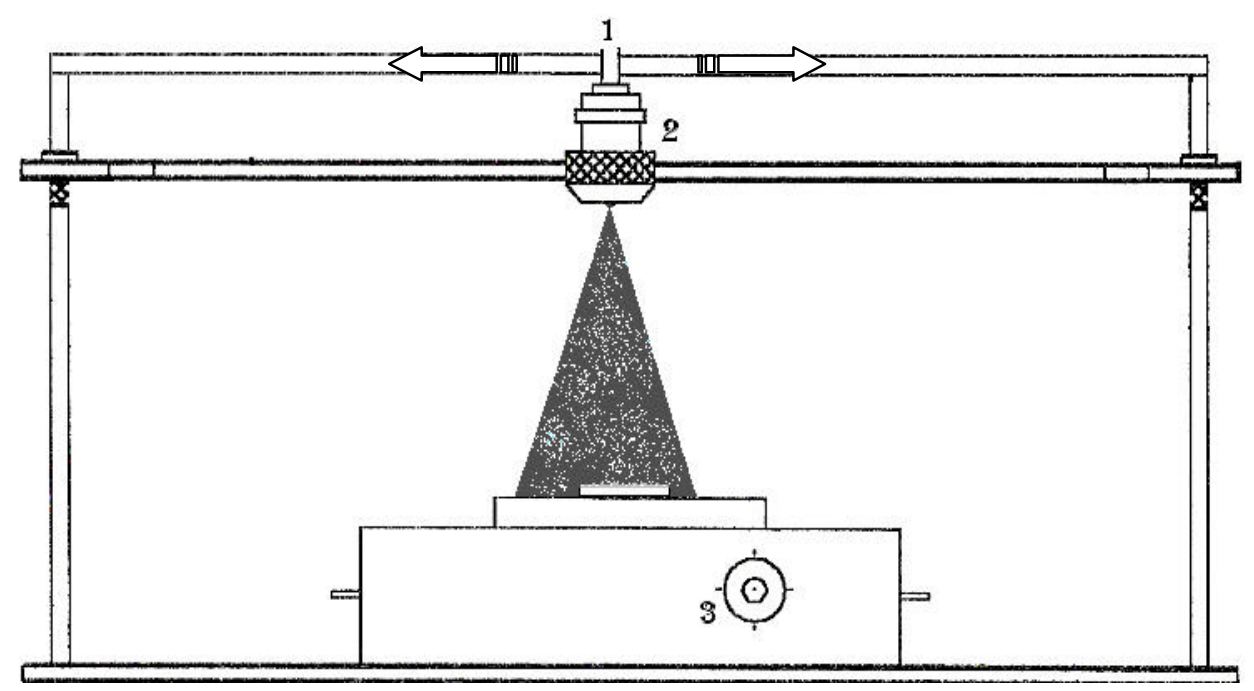

Figura 1: Esquema da modificação realizada no sistema de deposição

\subsection{Análise morfológica e estrutural}

A caracterização estrutural foi realizada com a técnica de difração de raios X (DRX), utilizando o difratômetro de raios-X, modelo URD 65 Freiberg com radiação de 1,78897 $\left(\mathrm{K}_{\mathrm{a}} \mathrm{Co}\right)$, pertencentes ao laboratório de Ciências Físicas/CCT/UENF.Através dos difratogramas foram identificadas as fases e os parâmetros cristlográficos dos filmes de ZEI, através da comparação com o padrão JCPDS \# 821246 para YSZ 8,8\% em mol após o tratamento térmico.

A análise morfológica foi realizada através das técnicas de microscopia ótica utilizando microscópio ótico NEOPHOT-32 com sistema de captação de imagem com câmera CCD acoplado instalado no Laboratório de Análise Metalográfica do LAMAV/CCT/UENF e imagens de microscopias de força atômica (AFM), operando-se o microscópio de sonda de varredura Nanoscope III da Digital Instruments, pertencente ao Laboratório Nacional de luz Síncroton (LNLS). Nas análises de imagens de microscopia ótica foi utilizado o programa ImageJ que possibilitou quantificar propriedades morfológicas como: a granulometria (valores normalizados), quantidade de partículas salinas e textura (valores normalizados a 1). Para as microscopias de AFM utilizou-se o software Nanoscope visando o estudo da rugosidade, homogeneidade e tamanho dos grãos presentes nos filmes de ZEI depositados pelo sistema tradicional e o modificado, para a temperatura de deposição e tratamento térmico utilizado. Foram realizados diversos ensaios de varreduras de AFM em regiões diferentes da amostra dentro de uma área de $1,0 \times 1,0 \mu \mathrm{m}^{2}$ para a região analisada, com uma força de contato de aproximadamente $80 \mathrm{nN}$. As medições foram realizadas em condições ambientais controladas com umidade relativa de $43 \%$ e temperatura de $26^{\circ} \mathrm{C}$.

\section{RESULTADOS E DISCUSSÃO}

\subsection{Caracterização estrutural}

A Figura 2 apresenta o difratograma de raios-X obtido para o filme de ZEI 8\% em mol depositado em substratos de quartzo, por um período de 30 minutos pelo sistema modificado, tratado termicamente a 
1000 0C/4 horas. Nesta Figura todos os picos apresentaram predominantes picos da fase cúbica, tipo fluorita, indexados pelo padrão JCPDS \# 82-1246. É importante frisar que há autores [19-20] que atribuem estes picos identificados a uma pseudofase cúbica, que é formada de uma fase metaestável tetragonal, cuja identificação por DRX não seria possível, mas sua condutividade elétrica é menor que do sistema cúbico [17-20].

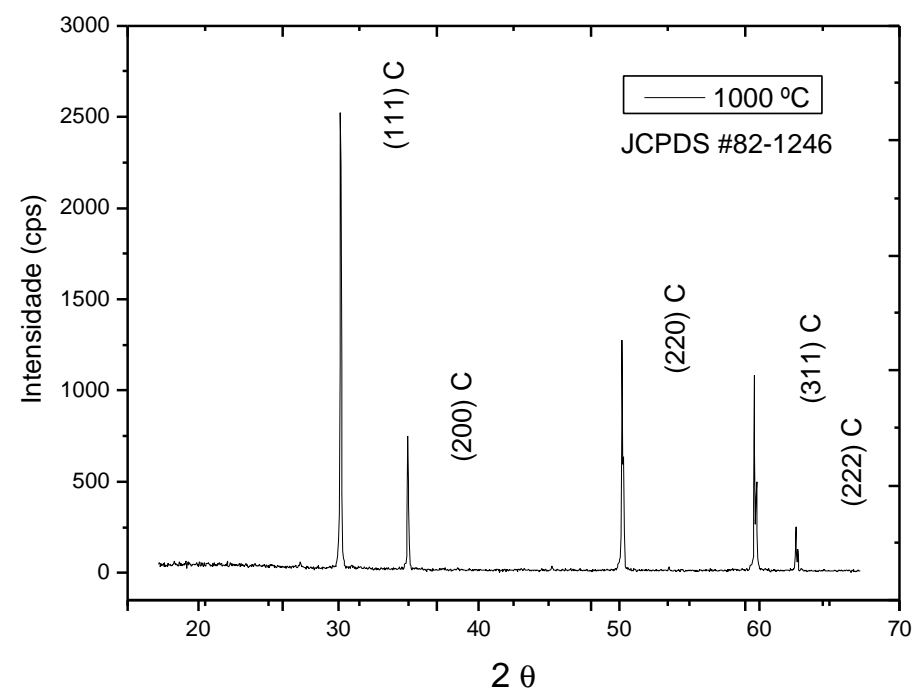

Figura 2: Difratograma para filme de ZEI 8\% em mol depositado pelo sistema MESP

As constantes de rede " $a$ " para o filme ZEI $8 \%$ em mol foram calculadas usando os picos (111), (200) e (220), encontrando-se na média o valor de 5,129 , com desvio padrão abaixo $1,5 \%$ em relação ao valor do padrão JCPDS, conforme verificado na Tabela 1. O cálculo de FWHM e do volume da célula unitária realizados com o programa FULLPROF foram 40,927 e 135,148 A, respectivamente, conforme confirma os valores expressos na Tabela 1. Através do calculo da razão dos parâmetros de rede c/a pelo programa FULLPROF verificou-se que os mesmos tendem para a unidade, o que corrobora com os dados da literatura [17-20], reforçando a suposição de que a rede está tendendo à estabilização total na forma cúbica.

Tabela 1: Parâmetros Cristalográficos dos Filmes ZEI 8\% em mol depositado pelo MESP®

\begin{tabular}{|c|c|c|c|}
\hline $\mathbf{2} \boldsymbol{\theta}$ & $\mathbf{h k l}$ & $\mathbf{a}(\mathbf{\AA})$ & $\Delta \mathbf{E} \%$ \\
\hline 30,16 & 111 & 5,127445 & 1,38 \\
\hline 34,96 & 200 & 5,128994 & 1,13 \\
\hline 50,24 & 220 & 5,132423 & 1,03 \\
\hline
\end{tabular}

\subsection{Caracterização morfológica}

Foram realizados estudos utilizando a técnica de microscopia ótica para os filmes de ZEI depositado pelo método tradicional e modificado, com os mesmos parâmetros de deposição, com aumento de 400 vezes em campo escuro e claro, apresentados nas Figuras 3 e 4. Na Figura 3(A) tem-se a imagem microscopia ótica que se comparada à Figura 3(B), indica o melhor controle dos parâmetros de deposição, indicado pela redução de partículas salinas na superfície do filme, quando utilizado o método de deposição modificado, para os filmes de ZEI depositados na temperatura de $350^{\circ} \mathrm{C}$. A presença de sais sobre a superfície dos filmes é indicativo que a temperatura de deposição está muito elevada, conforme descreveram Perednis et al [10], pois, a alta temperatura de deposição provoca a evaporação do solvente, aumento da concentração do soluto dentro das gotículas do spray, levando a solução a atingir o limite de solubilidade e consequiente a cristalização dos solutos antes de chegarem ao substrato, provocando a deposição de partículas salinas sobre os filmes. Observa-se na Figura 3B que maior quantidade de sal que formou-se sobre este filme, deve estar 
relacionado ao fato de no sistema de deposição modificado ter-se uma melhor distribuição de solução sobre o substrato, melhorando a distribuição de precipitados salinos sobre o filme, reduzindo as conseqüências deste efeito sobre a topologia dos filmes, quando comparados aos filmes depositados pelo sistema tradicional.

A análise das imagens da Figura 3 para filmes depositados pelo MESP® e pelo sistema tradicional de spray pirólise, com mesmo fluxo $(0,5 \mathrm{~mL} / \mathrm{min})$, temperatura de deposição $\left(300^{\circ} \mathrm{C}\right)$, variando o tempo de deposição, verificam-se filmes densos, isentos de trincas e fissuras, com partículas salinas na superfície.
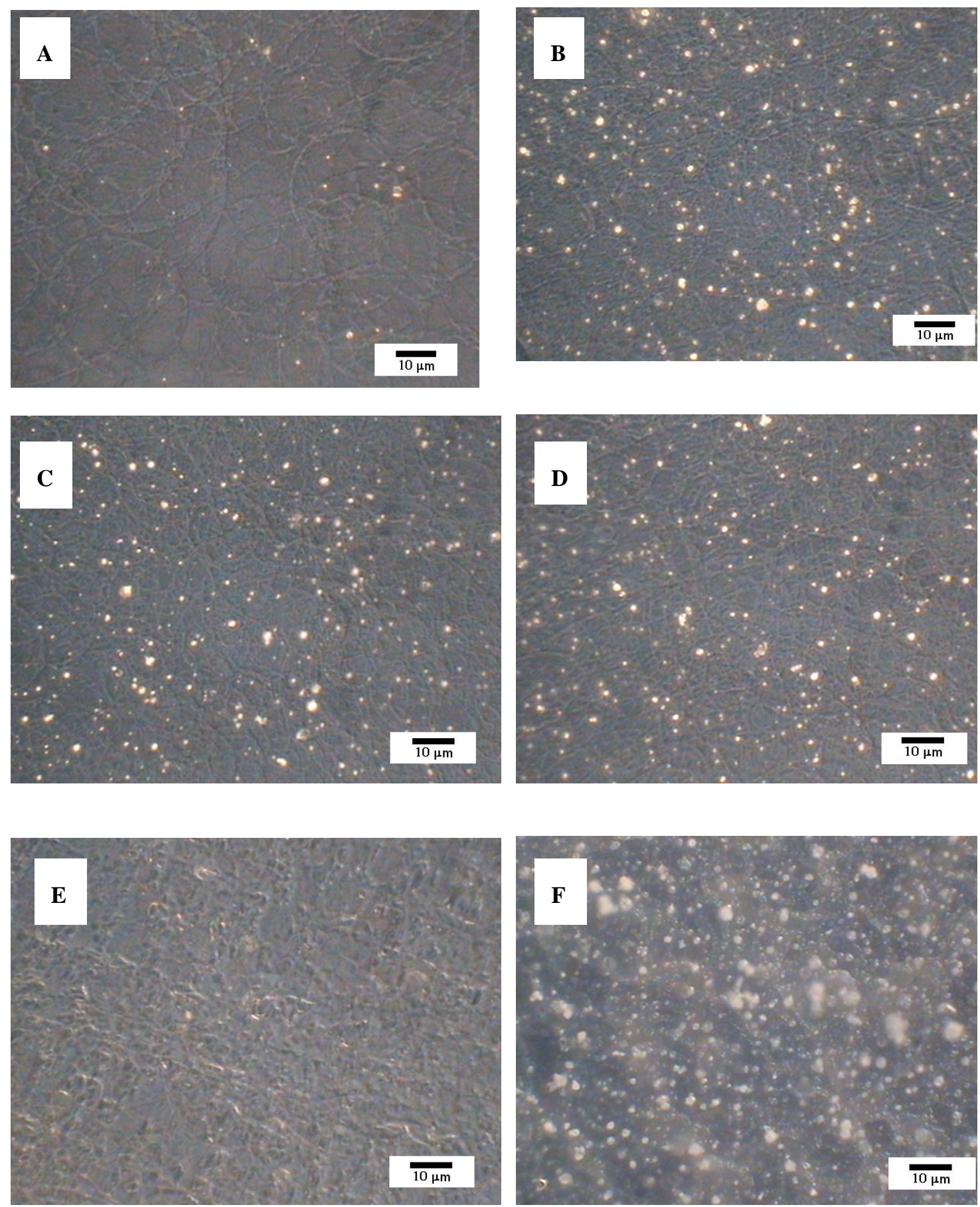

Figura 3: Imagens de microscopia ótica dos filmes depositados com 400X de aumento em campo escuro: 10 min - A) movimento e B) parado; 15 min - C) movimento e D) parado; 30 min - E) movimento e F) parado. 
Nas Figuras 3A e C, provenientes da deposição com MESP® em comparação as B e D, provenientes da deposição SP tradicional, fica evidente que o acumulo de partículas na superfície dos filmes é muito maior para esses últimos, implicando em maior rugosidade superficial destes filmes. Na Figura 3(E), depositado pelo sistema MESP®, observa-se um filme denso, praticamente isento de partículas salinas, mas com algumas deformações superficiais, provenientes da pequena espessura do filme, as quais são relacionadas à taxa de deposição. Para a Figura 3(F) depositado pelo sistema tradicional nas mesmas condições do filme citado anteriormente, verifica-se um filme denso e com grande acumulo de partículas salinas e maior rugosidade (evidenciado pela dificuldade de ajuste da distância focal), estando relacionado à elevada taxa de deposição do sistema, quando comparado com o filme depositado pelo MESP®.

Utilizando o Programa ImageJ foi possível obter parâmetros de granulometria, quantidade de partículas salinas e da textura dos filmes depositados, para das microscopias óticas dos filmes depositados pelo sistema tradicional e modificado, nos tempos de 15 e 30 minutos. Assim a partir das micrografias dos filmes depositados, com os mesmos parâmetros pelo sistema tradicional e o MESP®, foi possível resumir os dados apresentados na Tabela 2. Com estes resultados foi possível verificar que analisando o parâmetro granulométria para os filmes, independente do sistema de deposição de empregado (sp tradicional ou MESP®) tem-se valores equivalentes (dentro da margem de erro do software ImageJ), o que já era esperado, pois, a densidade de grãos sofre grandes mudanças quando se altera o tempo e/ou a temperatura de tratamento térmico.

Tabela 2: Resultados de Morfologia de Microscopia Ótica de Filmes ZEI

\begin{tabular}{|c|c|c|c|c|}
\hline Sistema & Amostra e Parâmetros & Granulometria & Partículas (un) & Textura \\
\hline \multirow{2}{*}{ MESP $®$} & $\mathbf{G 1 D}-300^{\circ} \mathrm{C}, 0,5 \mathrm{ml} / \mathrm{min}$ e $10 \mathrm{~min}$ & 0,69 & 313 & 0,02 \\
\cline { 2 - 5 } & $\mathbf{A 1}-300^{\circ} \mathrm{C}, 0,5 \mathrm{ml} / \mathrm{min}$ e $15 \mathrm{~min}$ & 0,79 & 505,00 & 0,05 \\
\hline \multirow{2}{*}{ SP Trad $-300^{\circ} \mathrm{C}, 0,5 \mathrm{ml} / \mathrm{min}$ e $30 \mathrm{~min}$} & 1,00 & 1177,00 & 0,08 \\
\cline { 2 - 5 } & $\mathbf{G 3 E}-300^{\circ} \mathrm{C}, 0,5 \mathrm{ml} / \mathrm{min}$ e $10 \mathrm{~min}$ & 0,72 & 759 & 0,91 \\
\cline { 2 - 5 } & $\mathbf{B 6}-300^{\circ} \mathrm{C}, 0,5 \mathrm{ml} / \mathrm{min}$ e $15 \mathrm{~min}$ & 0,78 & 523,00 & 0,93 \\
\hline
\end{tabular}

Observando-se os parâmetros textura e quantidade de partículas salinas (ver Tabela 2), verifica-se que o sistema MESP ${ }^{\circledR}$ apresenta-se com melhores resultados para a obtenção de filme para aplicação como eletrólito de ZEI. Verifica-se que a textura dos filmes depositados pelo sistema do sistema tradicional é de aproximadamente $60 \%$ maior do que para os filmes depositados em movimento, independente do tempo de deposição. Quanto ao número de partículas, em filmes depositados entre os dois tipos de sistema, têm-se um aumento de $3,6 \%$ e $13,4 \%$ para o sistema tradicional, nos tempos de 15 e 30 minutos de deposição, respectivamente. Estes resultados indicam que o número de partículas na superfície dos filmes, tende a aumentar com o tempo de deposição e mais rapidamente para o sistema parado.

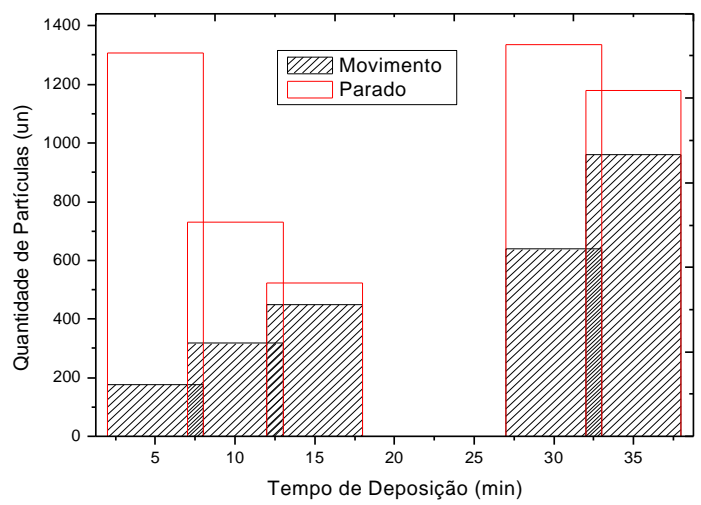

Figura 4: Gráfico da distribuição partículas vs o tempo para mês de ZEI com sistema tradicional e modificado. 
Na Figura 4 foi construído a curva mostrando o comportamento da distribuição de partículas salinas com o aumento do tempo de deposição para o sistema tradicional e o modificado, obtidos da análise das microscopias óticas no programa ImageJ. Observa-se que para ambos os sistemas, existem uma tendência de aumento do número de partículas salinas com o aumento do tempo de deposição. Entretanto, nos filmes depositados pelo sistema MESP®, o aumento do número de partículas é gradual. Este comportamento está relacionado ao melhor controle dos parâmetros de deposição, em especial, a temperatura e taxa de deposição. Fazendo com que as camadas de filmes nos sistema MESP® sejam melhor distribuídas, resultando em um filme mais homogêneo.

As micrografias de força atômica (ver Figura 5) revelaram que mudanças na morfologia, na rugosidade e na distribuição de grãos dos filmes de ZEI ocorreram quando os mesmos são depositados pelo sistema de spray-pirólise modificado e tradicional. Na Figura 5 têm-se as imagens de AFM de dois filmes de ZEI $8 \%$ em mol, depositados na temperatura de $300^{\circ} \mathrm{C}, 0,5 \mathrm{~mL} / \mathrm{min}$ de fluxo pelo tempo de 15 minutos e tratados termicamente a $1000^{\circ} \mathrm{C}$, no sistema modificado (Figura 5A) e no tradicional (Figura 5B). As micrografias de força atômica mostram que ambos os filmes têm como principais aspectos a ausência de porosidade aberta e de microtrincas, tamanho e formato de grãos uniformes, principalmente para os filmes depositados no sistema modificado (Figura 5A). Quanto à granulometria, fica evidenciada para a região analisada, a distribuição mais homogênea dos filmes depositados pelo MESP®, em relação ao filme depositado nas mesmas condições pelo sistema tradicional (Figura 5B); que apresenta ondulações e sobreposições de camadas de filmes de forma irregular. Estas variações topológicas, apresentando filmes com diferentes texturas quando variado vem a corroborar com os resultados apresentados na Tabela 2, indicando que o filme depositado pelo MESP® apresenta-se mais plano e com grãos melhor distribuídos. Estas diferenças podem estar relacionadas à melhor distribuição do spray durante a deposição quando usada técnica do MESP®. Nas Figuras $5 \mathrm{~A} / \mathrm{B}$ verifica-se que devido à ausência de zonas de fratura e/ou trincas, o mecanismo predominante de fratura deve ser o intergranular. Estes aspectos observados em escala nanometrica, vêm corroborar com as observações levantadas a partir das imagens de microscopia ótica, sobre o efeito positivo na morfologia pela implementação do sistema de deposição MESP®.
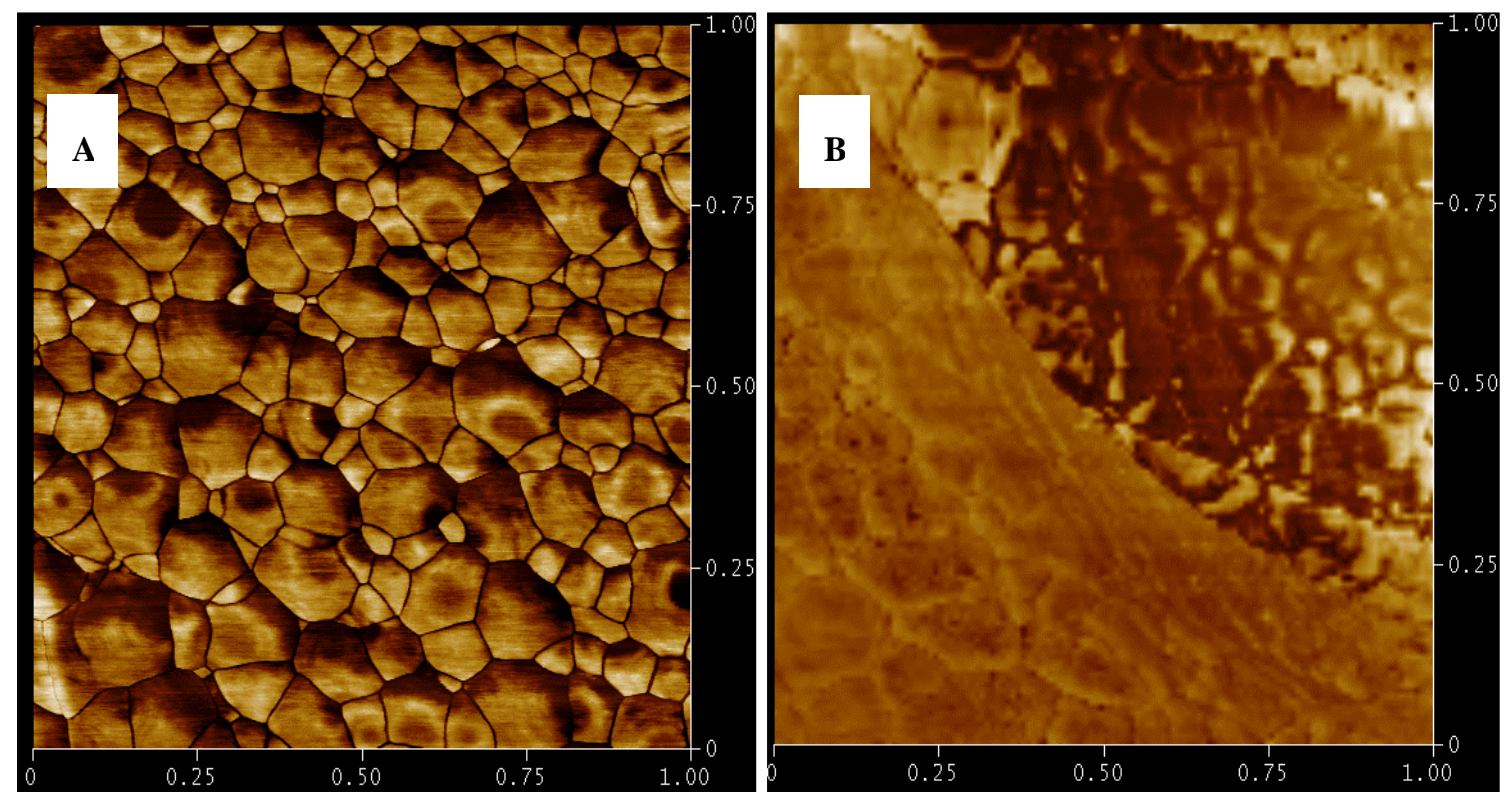

Figura 5: Microscopias de Força Atômica de Filmes ZEI 8\% em mol: A) MESP®; B) sistema tradicional

Os valores determinados através do software Nanoscope para os tamanhos médios de grãos destas cerâmicas indicadas na Figura 5 são 8,0 nm e 14,9 nm, para filmes depositados pelo MESP e pelo sistema tradicional, respectivamente. Sendo uma variação no tamanho do grão é cerca de $45 \%$ superior para filmes depositados nas mesmas condições pelo sistema tradicional.

Utilizando os recursos do software Nanoscope determinou-se a rugosidade superficial rms, para os filmes indicados nas imagens da Figura 5, depositados pelo MESP e pelo sistema tradicional, obtendo-se valores de 9,5 $\mathrm{nm}$ e 72,0 $\mathrm{nm}$, respectivamente. Constata-se com os resultados de rugosidade superficial RMS, o que já tinha sido observado nas imagens da Figura 5 e no resultados das análises de microscopia ótica apresentados na Tabela 2, que os filmes depositados pelo sistema MESP® apresentaram menor rugosidade, 
para a área analisada pelo microscópio de força atômica do que os filmes depositados pelo sistema spray pirólise tradicional

\section{CONCLUSÕES}

Neste trabalho foi demonstrado que filmes de ZEI $8 \% \mathrm{em}$ mol depositado em substratos de quartzo, apresentaram mudanças substanciais na topologia e morfologia quando depositados pela técnica de spraypirólise modificada (MESP®). Utilizando a técnica de DRX foi possível identificar que os picos encontramse indicando fase predominante cúbica do tipo fluorita para os filmes de ZEI 8\% em mol depositado tratados a $1000^{\circ} \mathrm{C}$. Nas análises realizadas a partir das imagens de microscopia ótica ficou evidenciado, que os filmes depositados pelo método modificado apresentaram menor quantidade de trincas, de partículas salinas superficiais e textura, o que está relacionado ao melhor controle dos parâmetros de deposição. Com micrografias de AFM determinou-se a rugosidade rms e o tamanho médio dos grãos dos filmes de ZEI $8 \%$ em mol, apresentando os melhores resultados os filmes depositados pelo sistema de deposição MESP®. Portanto, considerando os resultados apresentados considera-se que o sistema modificado foi capaz de prover mudanças positivas na topologia e morfologia dos filmes quando comparado ao sistema tradicional de spray pirólise.

\section{AGRADECIMENTOS}

Ao CNPq (Projeto PaCOS-TI, aprovado no edital 018 do CT-Energia/CNPq 504.694/2004-9, -CTEnergia/CNPq 554.766/2006-0 e CNPq -Universal/CNPq 472.191/2006-3) e CAPES pelo suporte financeiro. Ao MTA, pertencente ao Laboratório Nacional de luz Síncroton pelo suporte no AFM (LNLS, Brasil AFM\# 6954). Ao National Institutes of Health pelo desenvolvimento e liberação para domínio publico do programa ImageJ. Ao laboratório de ciências físicas localizado no CCT/UENF pela utilização do difratômetro de Raios-X e pelos difratogramas obtidos. Ao Laboratório de microscopia ótica pertencente ao LAMAV/CCT/UENF pelas microscopias ótica apresentadas e finalmente aos técnicos Carlan e Luis Antônio CCT/UENF por todo o apoio técnico essencial para as modificações do sistema de spray pirólise.

\section{BIBLIOGRAFIA}

[1] KURUMADA, M., HARA, H., IGUCHI, E., "Oxygen vacancies contributing to intragranular electrical conduction of yttria-stabilized zirconia (YSZ) ceramics", Acta Materialia, v. 53, pp. 4839-4846, 2005.

[2] ZHU, Q., FAN, B., "Low Temperature sintering of 8YSZ electrolyte film for intermediate temperature solid oxide fuel cell", Solid States Ionics, v. 176, pp. 889-894, 2006.

[3] PEREDNIS, G., WILHELM, O., PRATSINIS, S.E., GAUCKLER, L.J., "Morphology and deposition of thin yttria-stabilized zirconia films using spray pyrolysis", Thin solid films, v. 474, pp. 84-95, 2005.

[4] MEDEIROS, M.E., AMADO, R.S., MALTA, L.F.B., GARRIDO, F.M.S., "Pilhas a combustível de óxido sólido: materiais, componentes e configurações", Química Nova, v. 30, n. 1, pp. 189-197, 2007.

[5] GAUDON, M., DJURADO, E., MENZLER, N.H., "Morphology and sintering behavior of yttria stabilized zirconia (8-YSZ) powders synthesized by spray pyrolysis", Ceramics International, v. 30, pp. 2295-2303, 2004.

[6] CHARPENTIER, P., FRAGNAUD, F., SCHLEICH, D.M., GEHAIN, E., "Preparation of thin film SOFC working at reduced temperature”, Solid States Ionics, v. 135, pp. 373-380, 2000.

[7] GAUDON, M., DJURADO, E., MENZLER, N.H., "Morphology and sintering behavior of yttria stabilized zirconia (8-YSZ) powders synthesized by spray pyrolysis", Ceramics International, v. 30, pp. 2295-2303, 2004.

[8] SETOGUCHI, T., INOUE, T., TAKEBE, H., EGUCHI, E., MORINAGA, K., Arai, H., "Application of the stabilized zirconia thin film prepared by spray pyrolysis method to SOFC", Solid State Ionics, v. 37, pp. 217, 1990. 
[9] ACRES, G.J.K., "Recent advances in fuel cell technology and its applications", Journal of Power Sources, v. 100, pp. 60-66, 2001.

[10] PEREDNIS, G., GAUCKLER, L., "Solid oxide fuel cells with electrolytes prepared via spray pyrolysis", Solid States Ionics, v. 166, pp. 229-239, 2004.

[11] WEBER, A., IVERS-TIFFÉE, E., "Materials and Concepts for solid oxide fuel cells (SOFCs) in stationary and mobile applications", Journal of Power Sources, v. 127, pp. 273-283, 2004.

[12] WENDT, H., LINARD, M., ARICÓ, E.M., "Células a combustível de baixa potência para aplicações estacionárias", Química Nova, v. 25, n. 3, maio, 2002.

[13] HAILE, S.M., "Fuel cell materials and components", Acta Materialia, v. 51, pp. 5981-6000, 2003.

[14] HELlMAN, H.L., HOED, R., "Characterizing fuel cell technology: Challenges of the commercialization process", International Journal of Hydrogen Energy, v. 32, pp. 305 - 315, 2007.

[15] RODRIGUES, C.H.M., PAES JR, H.R., "Aparelho eletromecânico móvel de spray pirólise com leitura a laser para revestimento de superfície”, patente depositada no INPI em junho-2006.

[16] SOUZA, J., SILVA, A.G.P., PAES JR, H.R., "Synthesis and characterization of $\mathrm{CeO} 2$ thin films deposited by spray pyrolysis"; Journal of Material Science: Material Electronic, v. 18, pp. 951-956, 2007.

[17] TADOKORO, S.K., MUCCILLO, E.N.S., "Zircônia tetragonal policristalina. Parte II: Microestrutura e resistividade elétrica”, Cerâmica, v. 47, n. 302, São Paulo, 2001.

[18] DE FLORIO, D.Z., FONSECA, F.C., MUCCILLO, E.N.S., MUCCILLO, R., "Materiais cerâmicos para células a combustível”, Cerâmica, v. 50, n. 316, pp. 275-290, 2004.

[19] FUJIMORI, H., YASHIMA, M., SASAKI, S., KAKIHANA, M., MORI, T., TANAKA, M., YOSHIMURA, M., "Cubic-tetragonal phase change of yttria-doped hafnia solid solution: highresolution X-ray diffraction and Raman scattering", Chemical Physics Letters, v. 346, pp. 217-223, 2001.

[20] YASHIMA, M., KAKIHANA, M., YOSHIMURA, M., "Metastable-stable phase diagrams in the zirconia-containing systems utilized in solid-oxide fuel cell application", Solid States Ionics, v. 8688, pp. 1131-1149, 1996. 